\title{
An efficient non-Lambertian organic light-emitting diode using imprinted submicron- size zinc oxide pillar arrays
}

S. W. Liu, J. X. Wang, Y. Divayana, K. Dev, S. T. Tan, H. V. Demir, and X. W. Sun

Citation: Appl. Phys. Lett. 102, 053305 (2013);

View online: https://doi.org/10.1063/1.4791786

View Table of Contents: http://aip.scitation.org/toc/apl/102/5

Published by the American Institute of Physics

\section{Articles you may be interested in}

Improved light out-coupling in organic light emitting diodes employing ordered microlens arrays

Journal of Applied Physics 91, 3324 (2002); 10.1063/1.1435422

A high-extraction-efficiency nanopatterned organic light-emitting diode

Applied Physics Letters 82, 3779 (2003); 10.1063/1.1577823

Organic electroluminescent diodes

Applied Physics Letters 51, 913 (1998); 10.1063/1.98799

Nearly $100 \%$ internal phosphorescence efficiency in an organic light-emitting device

Journal of Applied Physics 90, 5048 (2001); 10.1063/1.1409582

Nano-honeycomb structured transparent electrode for enhanced light extraction from organic light-emitting diodes

Applied Physics Letters 106, 223301 (2015); 10.1063/1.4922040

Organic light emitting devices with enhanced outcoupling via microlenses fabricated by imprint lithography

Journal of Applied Physics 100, 073106 (2006); 10.1063/1.2356904

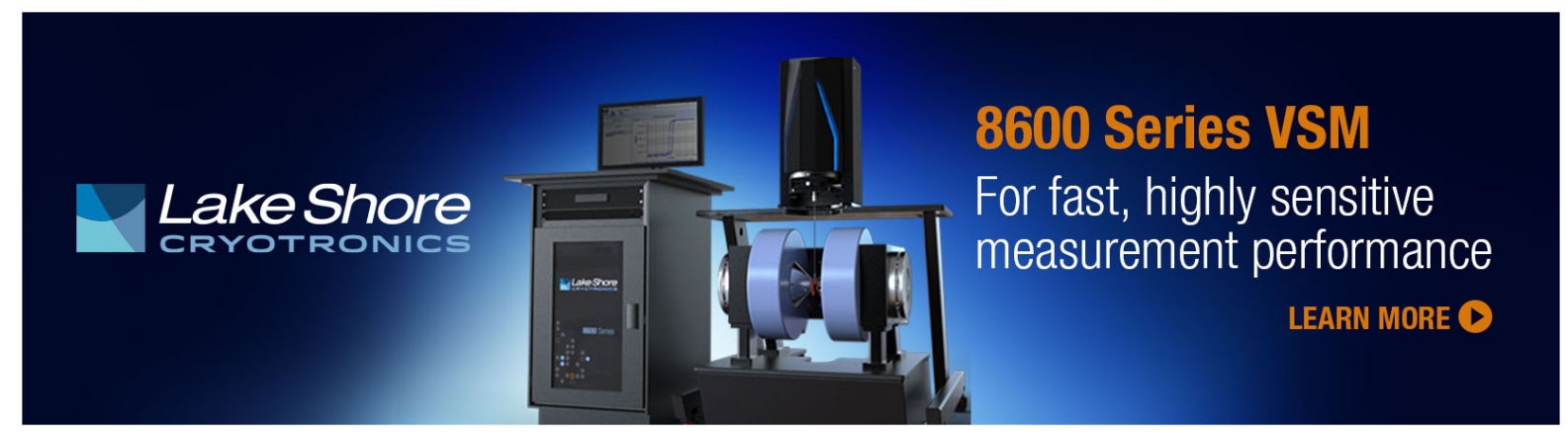




\title{
An efficient non-Lambertian organic light-emitting diode using imprinted submicron-size zinc oxide pillar arrays
}

\author{
S. W. Liu, ${ }^{1}$ J. X. Wang, ${ }^{1}$ Y. Divayana, ${ }^{1,2}$ K. Dev, ${ }^{1}$ S. T. Tan, ${ }^{1}$ H. V. Demir ${ }^{1,3,4, a)}$ \\ and X. W. Sun ${ }^{1,5, b)}$ \\ ${ }^{1}$ LUMINOUS! Center of Excellence for Semiconductor Lighting and Displays, School of Electrical \\ and Electronic Engineering, Nanyang Technological University, Nanyang Avenue, Singapore 639798 \\ ${ }^{2}$ School of Electrical Engineering, Udayana University, Kampus Bukit Jimbaran, Bali, Indonesia \\ ${ }^{3}$ School of Physical and Mathematical Sciences, Nanyang Technological University, Nanyang Avenue, \\ Singapore 639798 \\ ${ }^{4}$ Departments of Electrical and Electronics Engineering and Physics, UNAM-National Nanotechnology \\ Research Center, Bilkent University, Bilkent, Ankara 06800, Turkey \\ ${ }^{5}$ South University of Science and Technology, 1088 Xue-Yuan Road, Shenzhen, Guangdong 518055, China
}

(Received 31 October 2012; accepted 29 January 2013; published online 8 February 2013)

\begin{abstract}
We report phosphorescent organic light-emitting diodes with a substantially improved light outcoupling efficiency and a wider angular distribution through applying a layer of zinc oxide periodic nanopillar arrays by pattern replication in non-wetting templates technique. The devices exhibited the peak emission intensity at an emission angle of $40^{\circ}$ compared to $0^{\circ}$ for reference device using bare ITOglass. The best device showed a peak luminance efficiency of $95.5 \pm 1.5 \mathrm{~cd} / \mathrm{A}$ at $0^{\circ}$ emission (external quantum efficiency-EQE of $38.5 \pm 0.1 \%$, power efficiency of $127 \pm 1 \mathrm{~lm} / \mathrm{W}$ ), compared to that of the reference device, which has a peak luminance efficiency of $68.0 \pm 1.4 \mathrm{~cd} / \mathrm{A}$ (EQE of $22.0 \pm 0.1 \%$, power efficiency of $72 \pm 1 \mathrm{~lm} / \mathrm{W})$. (C) 2013 American Institute of Physics.

[http://dx.doi.org/10.1063/1.4791786]
\end{abstract}

Organic light-emitting diodes (OLEDs) have attracted great interest because of their great potential in display and lighting industries. Even though a 100\% internal quantum efficiency (IQE) has been realized by using phosphorescent emitters, ${ }^{1}$ the external quantum efficiency (EQE) encounters a bottleneck, which is due to the low light extraction efficiency. In conventional OLEDs in a planar waveguide-like structure, because of the refractive index difference between organics $(n \approx 1.8)$ and ITO (1.8), glass substrate $(1.5)$, and air $(1.0),{ }^{2}$ total internal reflection (TIR) occurs at the organic/ITO-glass substrate and glass-air interfaces. This results in about $50 \%$ of internally generated light being trapped in the organic/ITO layers (organic/ITO mode), and about $30 \%$ are trapped in the glass substrate (glass mode). Therefore, only around $20 \%$ of internally generated photons can be extracted into air. ${ }^{3-5}$

The low light extraction efficiency of OLEDs leaves much room for improvement. Techniques such as substrate roughening $^{6}$ and microlens array $(\mathrm{MLA})^{7,8}$ were applied to the backside of glass substrate to outcouple the glass mode, while techniques like photonic crystals (PCs), ${ }^{9,10}$ low index gridding, ${ }^{11-13}$ and corrugation structures ${ }^{14,15}$ were commonly introduced inside the OLEDs structure to extract light trapped in the organic/ITO mode. Among the above mentioned techniques, PCs attracted much attention because of their capability to control photons in various ways by designing different photonic nanostructures. 9,10,16,17 However, most of these techniques involve several steps necessary for fabricating PCs such as chemical vapour deposition (CVD), electron beam (EB) lithography, and reactive ion etching (RIE), etc., ${ }^{9}$ which are very time consuming and cost inefficient for

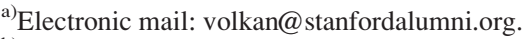

b)Electronic mail: exwsun@ntu.edu.sg.
}

industrial production. The pattern replication in non-wetting templates (PRINTs) technique, ${ }^{16,18,19}$ in contrast, is a simple, cost-effective method to fabricate the PC gratings with high throughput.

In this paper, we proposed and demonstrated nano-meter sized zinc oxide $(\mathrm{ZnO})$ pillars prepared by the PRINT technique at the backside of glass substrate as the light extraction medium for OLEDs. Significant improvement was achieved compared to the reference device using bare ITO-glass. The best device shows a maximum emission intensity level at $40^{\circ}$ viewing angle. At $0^{\circ}$ viewing angle, it yields a maximum luminous efficacy of $95.5 \pm 1.5 \mathrm{~cd} / \mathrm{A}$, which corresponds to $40.4 \%$ improvement compared to that of the reference device $(68.0 \pm 1.4 \mathrm{~cd} / \mathrm{A})$ measured at $0^{\circ}$. When integrated over all viewing angles, we achieved an EQE of $38.5 \pm 0.1 \%$ (power efficiency of $127 \pm 1 \mathrm{~lm} / \mathrm{W}$ ), corresponding to about $75 \%$ enhancement in total light output. Both two-dimensional Lumerical finite difference time domain (FDTD) simulation and numerical fitting using diffraction theory were carried out to verify the experimental results. The improvement is attributed to the combined effects of diffraction grating and higher extraction probability due to the light incident on vertical walls of the $\mathrm{ZnO}$ nanopillars. Furthermore, the light extraction efficiency is more sensitive to the variation in filling factor at lower fill factor (FF) value as compared to higher values.

Figure 1(a) briefly illustrates the PRINT technique used to fabricate submicron-size $\mathrm{ZnO}$ pillar array. Polydimethylsiloxane (PDMS) mold was first prepared using the patterned silicon master substrate, and then the PDMS mold was pressed on the backside of patterned ITO glass substrate pre-drop-casted with $\mathrm{ZnO}$ solgel nanoparticles, holding at constant pressure.

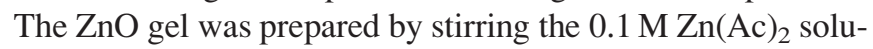
tion at $60^{\circ} \mathrm{C}$ for $10 \mathrm{~h}$ and then filtered by a filter paper with a 


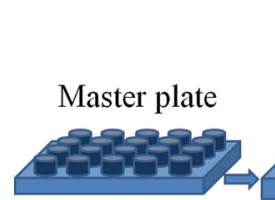

(i)

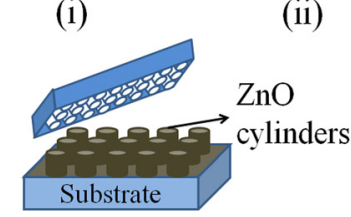

(v)

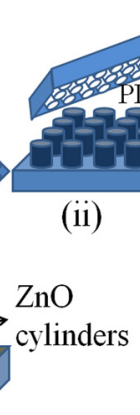

(ii) $\longleftrightarrow$

(a)
$\mathrm{ZnO}$ precursor solution

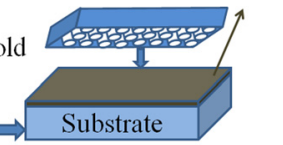

(iii)

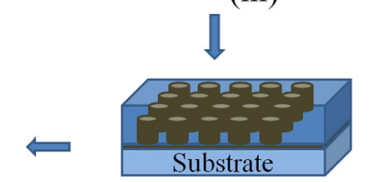

(iv)

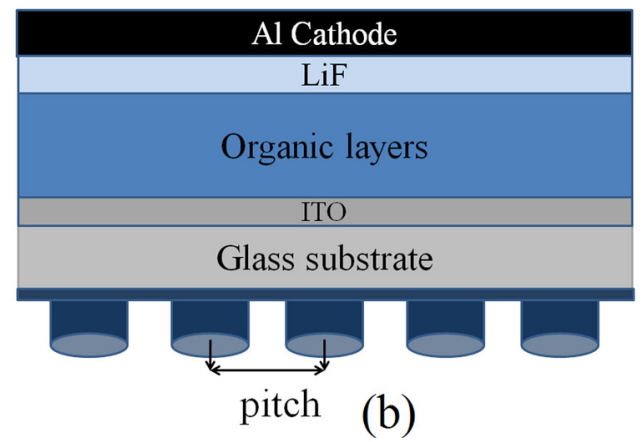

FIG. 1. (a) PRINT process used to fabricate $\mathrm{ZnO}$ nanopillar array and (b) schematic illustration of the OLED stacks with $\mathrm{ZnO}$ nanopillar array at the back side of glass.

pore size of $400 \mathrm{~nm}$. Following the application of the mold on $\mathrm{ZnO}$ solgel, the substrate was then heated for solvent evaporation. Subsequently, the mold was peeled off, leaving behind the periodical pillar arrays. Finally, the as-prepared substrate was annealed at $250^{\circ} \mathrm{C}$ for $0.5 \mathrm{~h}$ to obtain the $\mathrm{ZnO}$ pillars array.

OLEDs were fabricated with the following device structure: $\mathrm{ITO} / \mathrm{MoO}_{3}(20 \mathrm{~nm}) / 4,4^{\prime}, 4^{\prime \prime}$-tris (N-carbazolyl) triphenylamine (TCTA) $(60 \mathrm{~nm}) / 4,4^{\prime}-\mathrm{N}, \mathrm{N}^{\prime}$-dicarbazole-biphenyl $(\mathrm{CBP})$ : $f a c$ tris (2-phenyl-pyridinato-N, $\left.\mathrm{C}^{2^{\prime}}\right)$ iridium $\left(\operatorname{Ir}(\mathrm{ppy})_{3}\right)$ $(5 \%, 20 \mathrm{~nm}) / 1,3,5$-tris(N-phenylbenzimidazole-2-yl)benzene (TPBI) $(50 \mathrm{~nm}) / \mathrm{LiF}(1 \mathrm{~nm}) / \mathrm{Al}(100 \mathrm{~nm})$, where $\mathrm{MoO}_{3}$ was used as the hole injection layer (HIL), TCTA as the hole transport layer (HTL), CBP: $\operatorname{Ir}(\mathrm{ppy})_{3}$ as the emissive layer (EML), TPBI as the electron transport layer (ETL), LiF as the electron injection layer (EIL), and $\mathrm{Al}$ as the cathode. For the reference device, OLEDs stacks were fabricated on plain glass substrate without using any light outcoupling structure, while the test devices were fabricated on the glass substrate with their backsides pre-coated with $\mathrm{ZnO}$ pillar arrays with the pitches of $400 \mathrm{~nm}, 500 \mathrm{~nm}, 650 \mathrm{~nm}$, and $800 \mathrm{~nm}$, respectively. A schematic diagram of the device structure with the $\mathrm{ZnO}$ pillar array is shown in Figure 1(b). The radii and heights of the $\mathrm{ZnO}$ cylindrical pillars were designed to be fixed around $200 \mathrm{~nm}$. While the pitches of the $\mathrm{ZnO}$ pillar arrays were measured to be $400 \mathrm{~nm}, 500 \mathrm{~nm}, 650 \mathrm{~nm}$, and $800 \mathrm{~nm}$ as indicated by the SEM images shown in Figures 2(a)-2(d), respectively.

Figure 3 shows the luminance versus voltage $(\mathrm{L}-\mathrm{V})$ and current efficiency versus current density (CE-J) for the reference device and the test devices, while the inset shows their normalized emission spectra. The performance of various devices was measured at $0^{\circ}$ viewing angle (perpendicular to
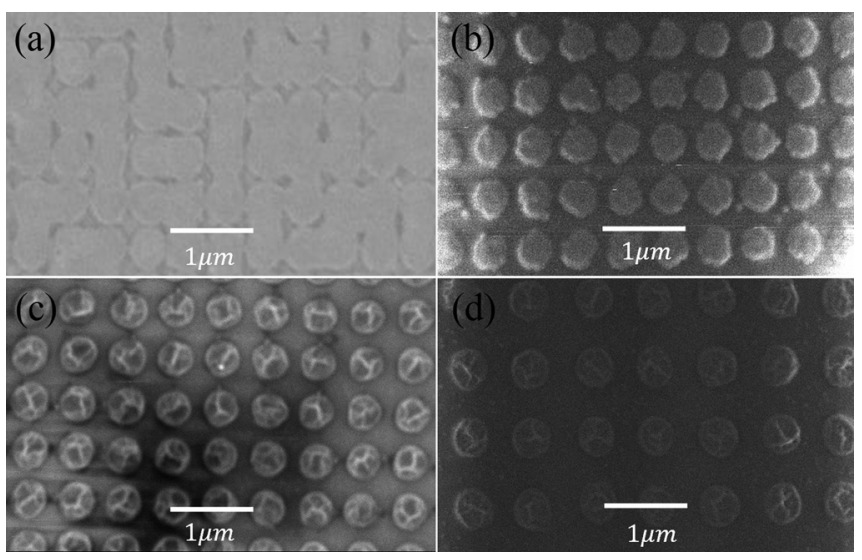

FIG. 2. SEM images of the $\mathrm{ZnO}$ nanopillar array with pitch of (a) $400 \mathrm{~nm}$, (b) $500 \mathrm{~nm}$, (c) $650 \mathrm{~nm}$, and (d) $800 \mathrm{~nm}$, respectively.

the emitting surface). From Figure 3(a), it can be seen that different devices have different luminance behavior, device with $650 \mathrm{~nm} \mathrm{ZnO}$ pillar pitch exhibits the largest luminance, and its luminance reaches $8442 \pm 100 \mathrm{~cd} / \mathrm{m}^{2}$ when the applied voltage (current density) is $6.43 \mathrm{~V}\left(10 \mathrm{~mA} / \mathrm{cm}^{2}\right)$. Under the same electrical conditions, device with the $\mathrm{ZnO}$ pillar pitch of $400 \mathrm{~nm}, 500 \mathrm{~nm}$, and $800 \mathrm{~nm}$ also exhibits an improved luminance level of $6916 \pm 200 \mathrm{~cd} / \mathrm{m}^{2}, 7331$ $\pm 128 \mathrm{~cd} / \mathrm{m}^{2}$, and $6325 \pm 75 \mathrm{~cd} / \mathrm{m}^{2}$, respectively, compared to the reference device that shows a luminance of 6041 $\pm 16 \mathrm{~cd} / \mathrm{m}^{2}$. The enhanced performance of tested devices implies higher light extraction efficiency compared to the reference device. The current efficiency also differs significantly for different devices. For example, at $0^{\circ}$ viewing angle, device with $650 \mathrm{~nm}$ pitch exhibits a maximum efficiency of $95.5 \pm 1.5 \mathrm{~cd} / \mathrm{A}$. This corresponds to $40.4 \%$ improvement as compared to that of the reference device, which shows a maximum current efficiency of $68.0 \pm 1.4 \mathrm{~cd} / \mathrm{A}$, while devices with $400 \mathrm{~nm}, 500 \mathrm{~nm}$, and $800 \mathrm{~nm}$ pitches show maximum current efficiencies of $77.8 \pm 0.6 \mathrm{~cd} / \mathrm{A}, 82.6$ $\pm 3.4 \mathrm{~cd} / \mathrm{A}, 73.7 \pm 0.1 \mathrm{~cd} / \mathrm{A}$, corresponding to an improvement of $14.4 \%, 21.5 \%$, and $8.4 \%$, respectively, compared to that of the reference device. The inset depicts the normalized spectra for the reference device and the tested devices. Corresponding to the efficiency improvement levels, we observed that device with $650 \mathrm{~nm}$ pitch has the most significantly different spectrum compared to the reference device, while the device with $500 \mathrm{~nm}$ pitch shows slightly less significant change in spectrum compared with that of the device
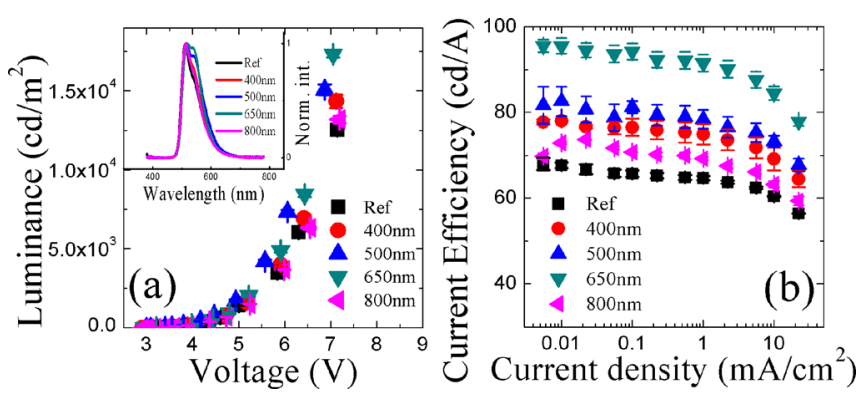

FIG. 3. (a) Luminance versus voltage (L-V) and (b) current efficiency versus current density (CE-J). Inset: normalized emission spectrum for reference device and devices with different pitches. 
with $650 \mathrm{~nm}$ pitch. Furthermore, both devices with $400 \mathrm{~nm}$ and $800 \mathrm{~nm}$ pitches show the least deviation from that of the reference device. The significance of change in spectrum follows the trend of efficiency improvement, the difference clearly arises from diffraction of light by the $\mathrm{ZnO}$ nanopillars, ${ }^{9,10,20}$ the deeper reason of the efficiency enhancement will be described with simulation in later paragraphs.

Figure 4(a) shows the normalized angular emission intensity for the reference and tested devices. The reference and devices with $400 \mathrm{~nm}$ and $800 \mathrm{~nm}$ pitches have similar angular distribution characteristics, where they both show the maximum emission intensity at the low emission angle (close to normal incidence) in a typical Lambertian emission pattern. This implies that the diffraction effect for devices with the pitch of $400 \mathrm{~nm}$ and $800 \mathrm{~nm}$ is not very significant. The devices with $500 \mathrm{~nm}$ and $650 \mathrm{~nm}$ pitches, however, show very different angular emission behaviors. For example, the device with $650 \mathrm{~nm}$ pitch shows its maximum emission intensity at an observation angle of $40^{\circ}$ and its emission intensity decreasing at only higher emission angles. Although the peak intensity of device with $500 \mathrm{~nm}$ pitch was detected at $0^{\circ}$ viewing angle, compared to reference device, it shows a broader emission at higher angles. The different angular emission behaviors could be explained by the grating effect of the $\mathrm{ZnO}$ pillar arrays shown below.

The presence of the periodic $\mathrm{ZnO}$ nanopillars enables the extraction of the trapped light into air. Diffracted light follows: $:^{21,22}$

$$
\lambda=p\left(\mathrm{n} \sin \theta_{i n}+\sin \theta_{d i f}\right),
$$

where $\lambda$ is the emission wavelength, $p$ is the pitch of $\mathrm{ZnO}$ pillar array, $n$ is the refractive index of the glass substrate, $\theta_{\text {in }}$ is the incident angle, and $\theta_{d i f}$ is the diffracted angle. From Eq. (1), if the incidence angle is $0^{\circ}$ (inset of Figure 4(d)), the emission intensity of the diffracted light becomes
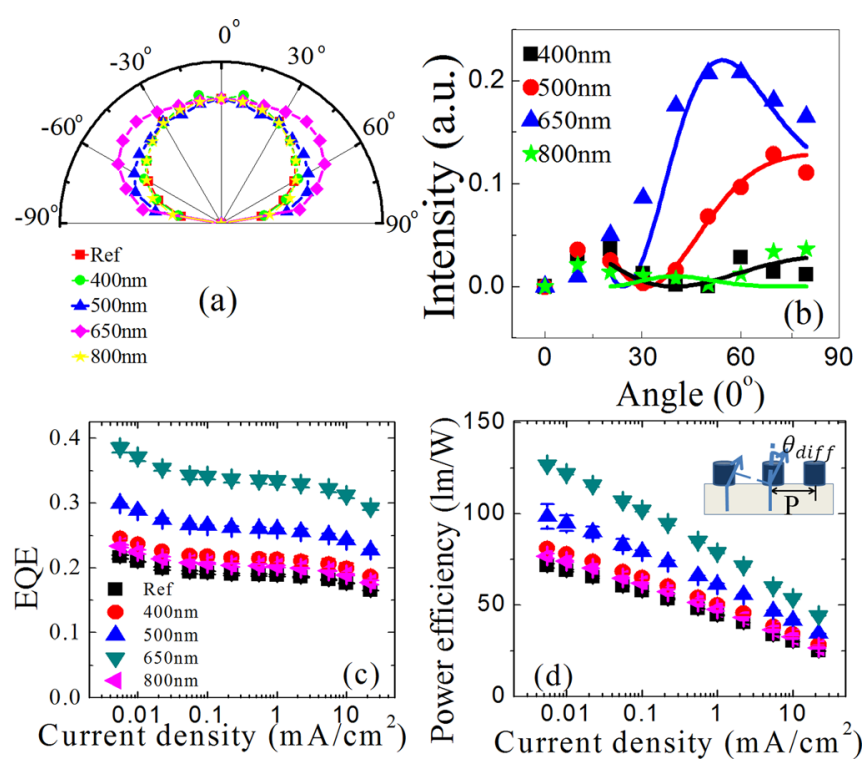

FIG. 4. (a) Normalized angular distributions of the reference device and device with different pitches. (b) Fitting of the angular distribution. (c) EQE versus current density and (d) power efficiency versus current density. Inset: Diffraction grating with the presence of $\mathrm{ZnO}$ nanopillar arrays.

$$
f(\theta)=A \times\left(\cos \left(\frac{\pi p}{\lambda} \times \sin (\theta)\right)\right)^{2}
$$

Here $A$ represents the amplitude of light extracted by the grating, $p$ is the pitch of $\mathrm{ZnO}$ pillar array, $\lambda$ is the wavelength, which is set to the peak wavelength $510 \mathrm{~nm}$ in this case, and $\theta$ is the emission angle viewed from air.

Figure 4(b) shows the intensity of the diffracted light emitted from the tested devices with different pitches as a function of the emission angle. These were obtained by subtracting the total angular emission for the corresponding device with that of the control device. The resulted curves were fitted using Eq. (2). The fitted lines show good agreement with the experimental results, especially for devices with $500 \mathrm{~nm}$ and $650 \mathrm{~nm}$ pitches. The constant $A$ resulted from fitting is $0.05,0.13,0.22$, and 0.01 for device with $400 \mathrm{~nm}$, $500 \mathrm{~nm}, 650 \mathrm{~nm}$, and $800 \mathrm{~nm}$ pitch, respectively. The much smaller fitting coefficient for device with $400 \mathrm{~nm}$ and $800 \mathrm{~nm}$ pitches further confirms both devices exhibit weaker diffraction grating effect.

The total number of photons emitted can be calculated by integrating the angular photon density over all angles. Figures 4(c) and 4(d) show the overall EQE and power efficiency versus current density. Here the best device $(650 \mathrm{~nm}$ pitch) leads to a maximum $\mathrm{EQE}$ (power efficiency) of $38.5 \pm 0.1 \%$ $(127 \pm 1 \mathrm{~lm} / \mathrm{W})$, significantly larger than that of the reference device, which show a maximum $\mathrm{EQE}$ (power efficiency) of $22.0 \pm 0.1 \%(72 \pm 1 \mathrm{~lm} / \mathrm{W})$, while device with $400 \mathrm{~nm}$, $500 \mathrm{~nm}$, and $800 \mathrm{~nm}$ pitch exhibits efficiency level of $24.6 \pm 0.1 \%(81.1 \pm 0.4 \mathrm{~lm} / \mathrm{W}), 29.9 \pm 0.1 \%(98.5 \pm 6.0 \mathrm{~lm} / \mathrm{W})$, and $23.3 \pm 0.1 \% \quad(76.8 \pm 1.3 \mathrm{~lm} / \mathrm{W})$, respectively. The improvement of EQE and power efficiency shown in Figure 4 is slightly different from that of the current efficiency in Figure 3(b), this is expected since current efficiency was measured at specific $0^{\circ}$ angle, while both $\mathrm{EQE}$ and power efficiency were integrated for all angles to take into account the non-Lambertian emission angular distribution characteristic of the tested devices.

To have better understanding of the physics behind the improvement, a two-dimensional Lumerical FDTD simulation was performed to verify the experiment results. A simulation area of $15 \mu \mathrm{m} \times 15 \mu \mathrm{m}$ is constructed to include multiple period of patterning. Dipole light source is placed in emission layer to replicate the light radiation generated due to electron-hole pair. Physically matched layers are used as boundary condition to surround the simulation area in order to absorb any light radiation impinging on it. $\mathrm{ZnO}$ nano-pillar array with $200 \mathrm{~nm}$ height and $200 \mathrm{~nm}$ radius is placed over the glass surface as shown in Fig. 1. The period of $\mathrm{ZnO}$ nano-pillar array is varied and light extraction efficiency (LEE) is measured at $510 \mathrm{~nm}$ wavelength in the farfield integrating all extracted light radiation in $1^{\circ}$ solid angle. Figures 5(a) and 5(b) show the intensity field distribution with propagation of the reference device and device with $\mathrm{ZnO}$ nanopillars, respectively. We can clearly see that light is escaping out of the glass surface due to the presence of $\mathrm{ZnO}$ nano-pillar array in comparison to light undergoing TIR from glass-air interface in conventional OLED structure. Figure 5(c) shows the light extraction efficiency versus fill 

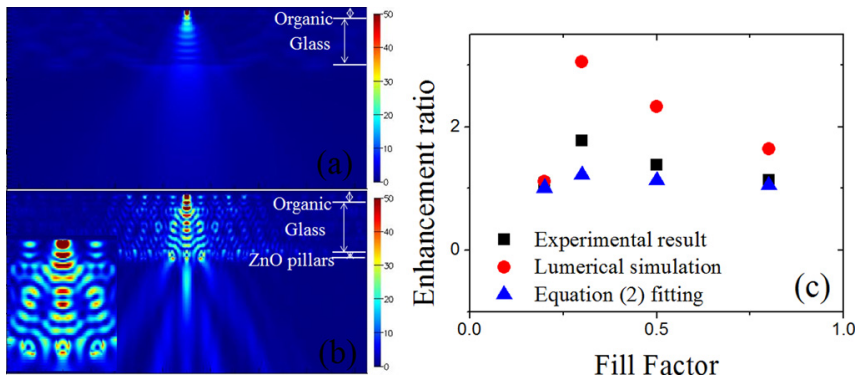

FIG. 5. Intensity field distribution with propagation of (a) reference OLED, (b) OLED with $\mathrm{ZnO}$ nanopillar array. (c) Experimental results of light extraction enhancement ratio with respect to fill factor in comparison with Lumerical FDTD simulation and fitting result using diffraction theory. Inset of (b): zoom-in image of field distribution.

factor (FF) for both numerical simulation using Lumerical FDTD and fitting results using Eq. (2) together with experimental data. Our experimental data show similar trend with the simulation results. The simulation deviates slightly from the simplified model using Eq. (2), this implies that pure diffraction grating effect may not be the only reason behind the improvement. Compared to the light that initially undergoes TIR in reference OLED, light in tested devices with incident angle larger than critical angle at $\mathrm{ZnO}$ /air interface now has more chance to be extracted if light incident on the $\mathrm{ZnO}$ pillars vertical walls, this could be observed clearly from the inset of Figure 5(b), which shows the zoom-in image of the field distribution, the much higher intensity surrounding the $\mathrm{ZnO}$ nanopillars indicates more light were outcoupled through the nanopillars. From the plot, we also observed that light extraction ratio is more sensitive to the variation of $\mathrm{FF}$ at lower FF value than that in larger region, the FF for cylindrical pillar shaped photonic crystal is calculated by

$$
F F=\frac{\pi r^{2}}{p^{2}},
$$

where $r$ is the radius of the nanopillar and $p$ is the pitch. The filling factor for $\mathrm{ZnO}$ pillars of $400 \mathrm{~nm}, 500 \mathrm{~nm}, 650 \mathrm{~nm}$, and $800 \mathrm{~nm}$ pitch is $0.8,0.5,0.3$, and 0.2 , respectively. Due to the inverse square proportional relation between the FF and pitch, a small FF change at lower limit equivalent to large variation in pitch. From the experiment results, PC grating resulted in significant drop in efficiency enhancement when the filling factor is too large or too small, which agrees with previous research. ${ }^{17}$

In conclusion, we have fabricated high efficiency OLEDs with $\mathrm{ZnO}$ pillar array at the backside of the glass substrate using PRINT technique. The device with the $\mathrm{ZnO}$ pillar array pitch of $650 \mathrm{~nm}$ (FF of 0.3 ) achieved a maximum EQE of $38.5 \pm 0.1 \%$, which corresponds to $75.0 \%$ enhancement in total light output. Furthermore, the best device reached a maximum current efficiency of $95.5 \pm 1.5 \mathrm{~cd} / \mathrm{A}$ measured at $0^{\circ}$ viewing angle, improved by $40.4 \%$ compared to the reference measured at the normal incidence. The improvement was attributed to the effective diffraction of light trapped in the glass mode by the $\mathrm{ZnO}$ nanopillar arrays.

This work is supported by the Singapore National Research Foundation under Grant No. NRF-CRP-6-2010-2 and NRF-RF-2009-09 and the Singapore Agency for Science, Technology and Research (A*STAR) SERC under Grant Nos. 0921010057 and No. 112120 2009. The work is also supported by the National Natural Science Foundation of China (NSFC) (Project Nos. 61006037, 61177014, and 61076015), and Tianjin Natural Science foundation (Project Nos. 11JCZDJC21900 and 11JCYDJC25800).

${ }^{1}$ M. A. Baldo, S. Lamansky, P. E. Burrows, M. E. Thompson, and S. R. Forrest, Appl. Phys. Lett. 75(1), 4 (1999).

${ }^{2}$ V. Bulovic, V. B. Khalfin, G. Gu, P. E. Burrows, D. Z. Garbuzov, and S. R. Forrest, Phys. Rev. B 58(7), 3730 (1998).

${ }^{3}$ R. Meerheim, M. Furno, S. Hofmann, B. Lussem, and K. Leo, Appl. Phys. Lett. 97(25), 253305 (2010).

${ }^{4}$ S. Y. Kim and J. J. Kim, Org. Electron. 11(6), 1010 (2010).

${ }^{5}$ C. Adachi, M. A. Baldo, M. E. Thompson, and S. R. Forrest, J. Appl. Phys. 90(10), 5048 (2001).

${ }^{6}$ J. H. Zhou, N. Ai, L. Wang, H. Zheng, C. Luo, Z. X. Jiang, S. F. Yu, Y. Cao, and J. A. Wang, Org. Electron. 12(4), 648 (2011).

${ }^{7}$ J. Lim, S. S. Oh, D. Y. Kim, S. H. Cho, I. T. Kim, S. H. Han, H. Takezoe, E. H. Choi, G. S. Cho, Y. H. Seo, S. O. Kang, and B. Park, Opt. Express 14(14), 6564 (2006).

${ }^{8}$ C. J. Yang, S. H. Liu, H. H. Hsieh, C. C. Liu, T. Y. Cho, and C. C. Wu, Appl. Phys. Lett. 91(25), 253508 (2007).

${ }^{9}$ Y. R. Do, Y. C. Kim, Y. W. Song, C. O. Cho, H. Jeon, Y. J. Lee, S. H. Kim, and Y. H. Lee, Adv. Mater. 15(14), 1214 (2003).

${ }^{10}$ K. Ishihara, M. Fujita, I. Matsubara, T. Asano, S. Noda, H. Ohata, A. Hirasawa, H. Nakada, and N. Shimoji, Appl. Phys. Lett. 90(11), 111114 (2007).

${ }^{11}$ Y. Sun and S. R. Forrest, Nat. Photon. 2(8), 483 (2008).

${ }^{12}$ T. W. Koh, J. M. Choi, S. Lee, and S. Yoo, Adv. Mater. 22(16), 1849 (2010).

${ }^{13}$ J. Choi, T. W. Koh, S. Lee, and S. Yoo, Appl. Phys. Lett. 100(23), 233303 (2012).

${ }^{14}$ Y. G. Bi, J. Feng, Y. F. Li, Y. Jin, Y. F. Liu, Q. D. Chen, and H. B. Sun, Appl. Phys. Lett. 100(5), 053304 (2012).

${ }^{15}$ W. J. Hyun, S. H. Im, O. O. Park, and B. D. Chin, Org. Electron. 13(4), 579 (2012).

${ }^{16}$ K. Ishihara, M. Fujita, I. Matsubara, T. Asano, and S. Noda, Jpn. J. Appl. Phys. Part 2 45(4-7), L210 (2006).

${ }^{17}$ Q. Y. Yue, W. Li, F. M. Kong, and K. Li, Adv. Mater. Sci. Eng. 2012, 985762 (2012).

${ }^{18}$ S. Y. Chou, P. R. Krauss, and P. J. Renstrom, Appl. Phys. Lett. 67(21), 3114 (1995)

${ }^{19}$ M. J. Hampton, S. S. Williams, Z. L. Zhou, J. Nunes, D. H. Ko, J. L. Templeton, J. M. DeSimone, and E. T. Samulski, Proc. SPIE 7047, 70470T (2008).

${ }^{20}$ Y. J. Lee, S. H. Kim, J. Huh, G. H. Kim, Y. H. Lee, S. H. Cho, Y. C. Kim, and Y. R. Do, Appl. Phys. Lett. 82(21), 3779 (2003).

${ }^{21}$ S. M. Jeong, F. Araoka, Y. Machida, Y. Takanishi, K. Ishikawa, H. Takezoe, S. Nishimura, and G. Suzaki, Jpn. J. Appl. Phys. 47(6), 4566 (2008).

${ }^{22}$ R. L. Pfleegor and L. Mandel, Phys. Rev. 159(5), 1084 (1967). 